\title{
Influence of Obesity on Outcomes of Surgery for Lumbar Spinal Canal Stenosis
}

\author{
Atsushi Furukawa ${ }^{1}$, Yuichi Kasai ${ }^{*}, 1, K$ Koji Akeda ${ }^{1}$, Eiji Nii ${ }^{2}$ and Atsumasa Uchida ${ }^{2}$ \\ ${ }^{I}$ Department of Orthopaedic Surgery, Mie University Graduate School of Medicine, Japan \\ ${ }^{2}$ Department of Orthopaedic Surgery, Mie Pref. Kusanomi Rehabilitation Center for Children, Japan
}

\begin{abstract}
Background: Obesity is likewise becoming more prevalent in patients with lumbar spinal canal stenosis, but few studies have examined relationships between obesity levels and surgical outcomes for this condition. The purpose of the present study is to determine the influence of body-mass index (BMI) on outcomes of surgery for lumbar spinal canal stenosis.

Materials and Methods: The subjects comprised 118 patients who had underwent posterolateral fusion in a single intervertebral disc space with spinal instrumentation using a pedicle screw and rod system. Obesity levels were classified into three groups according to BMI: $\geq 35$, severely obese group $(n=12) ; 25$ to $<35$, obese $(n=38)$; and $<25$, non-obese $(\mathrm{n}=68)$. Investigated items including operative time, volume of intraoperative bleeding, distance from skin surface to the posterior margin of the vertebral body, improvement rate of the Japanese Orthopaedic Association (JOA) scoring system for lumbar spinal disorders and intra- and postoperative complications were all compared between the three groups.

Results: Longer operative time, increased intraoperative bleeding, longer distance from the skin surface to the posterior margin of the vertebral body, poor postoperative outcomes and higher incidences of intra- and postoperative complications were observed with surgery for lumbar spinal canal stenosis in severely obese patients (BMI $\geq 35$ ), compared to patients with $\mathrm{BMI}<35$.

Conclusions: Severely obese patients and their family members should thus receive sufficient explanation of the risks associated with surgery when obtaining informed consent.
\end{abstract}

Keywords: Lumbar spinal canal stenosis, obesity, spine surgery.

\section{INTRODUCTION}

It is reported that various elements including the preoperative severity in the patient and duration of disease as well as the presence or absence of smoking [1], psychopsychiatric disposition [2] and problem of compensation [3], etc. are involved as the factors to influence the operation results of lumbar spinal canal stenosis. Especially in regard to the psychopsychiatric element, it is reported that surgical treatment did not improve the symptoms if the patient demonstrated anxiety, depression tendency and neurosis tendency $[4,5]$.

In recent years, the number of people suffering from obesity has been increasing, due to changes in dietary habits, insufficient exercise, and life under increased stress [6]. This phenomenon has been seen not only in Western countries, but also in Asian countries [7]. Obesity is likewise becoming more prevalent in patients with lumbar spinal canal stenosis [8], but few studies have examined relationships between obesity levels and surgical outcomes for this condition. The present study investigated the influence of body-mass index

*Address correspondence to this author at the Department of Orthopaedic Surgery, Mie University Graduate School of Medicine, 2-174 Edobashi, Tsu city, Mie prefecture, 514-8507, Japan; Tel: +81-59-231-5022; Fax: +81-59231-5211; E-mail: ykasai@clin.medic.mie-u.ac.jp
(BMI) on outcomes of surgery for lumbar spinal canal stenosis.

\section{SUBJECTS AND METHODS}

A total of 452 patients with lumbar spinal canal stenosis underwent surgery in our department or affiliated hospitals between 1998 and 2005. Of these, subjects comprised 118 patients (60 men, 58 women) who had been followed for $\geq 2$ years after undergoing posterolateral fusion in a single intervertebral disc space with spinal instrumentation using a pedicle screw and rod system. Exclusion criteria included spondylolysis and grade 2 or greater spondylolisthesis. Mean ( \pm standard deviation) age was $69.8 \pm 14.6$ years. All patients received surgery by a single surgeon. Bone graft was local bone alone or a mixture of local bone and artificial bone (OSferion; Olympus, Tokyo, Japan).

Concerning the degree of obesity, the BMI obesity scale employed by Japan Society for the Study of Obesity was used as the basis (BMI of $\geq 25<30$ as grade I, $\geq 30<35$ as grade II, $\geq 35<40$ as grade III and $\geq 40$ as grade IV). In this regard, the patients were roughly classified into 2 types, that is, those assessed as grade I and II (obese group) and those assessed as grade III and IV (severely obese group). Accordingly, the whole patients were classified into 3 groups of non-obese group, obese group and severely obese group. 
Table 1. Age at Operation and Gender of Patients in Each Group

\begin{tabular}{|c|c|c|}
\hline & Age at operation (years) & Gender (Cases) \\
\hline \hline non-obese group & $72.1 \pm 15.9$ & male 29 - female 39 \\
\hline obese group & $65.3 \pm 11.8$ & male 22 - female 16 \\
\hline severely obese group & $48.6 \pm 10.4 *$ & male 9 - female 3 \\
\hline
\end{tabular}

$* \mathrm{p}<0.01$.

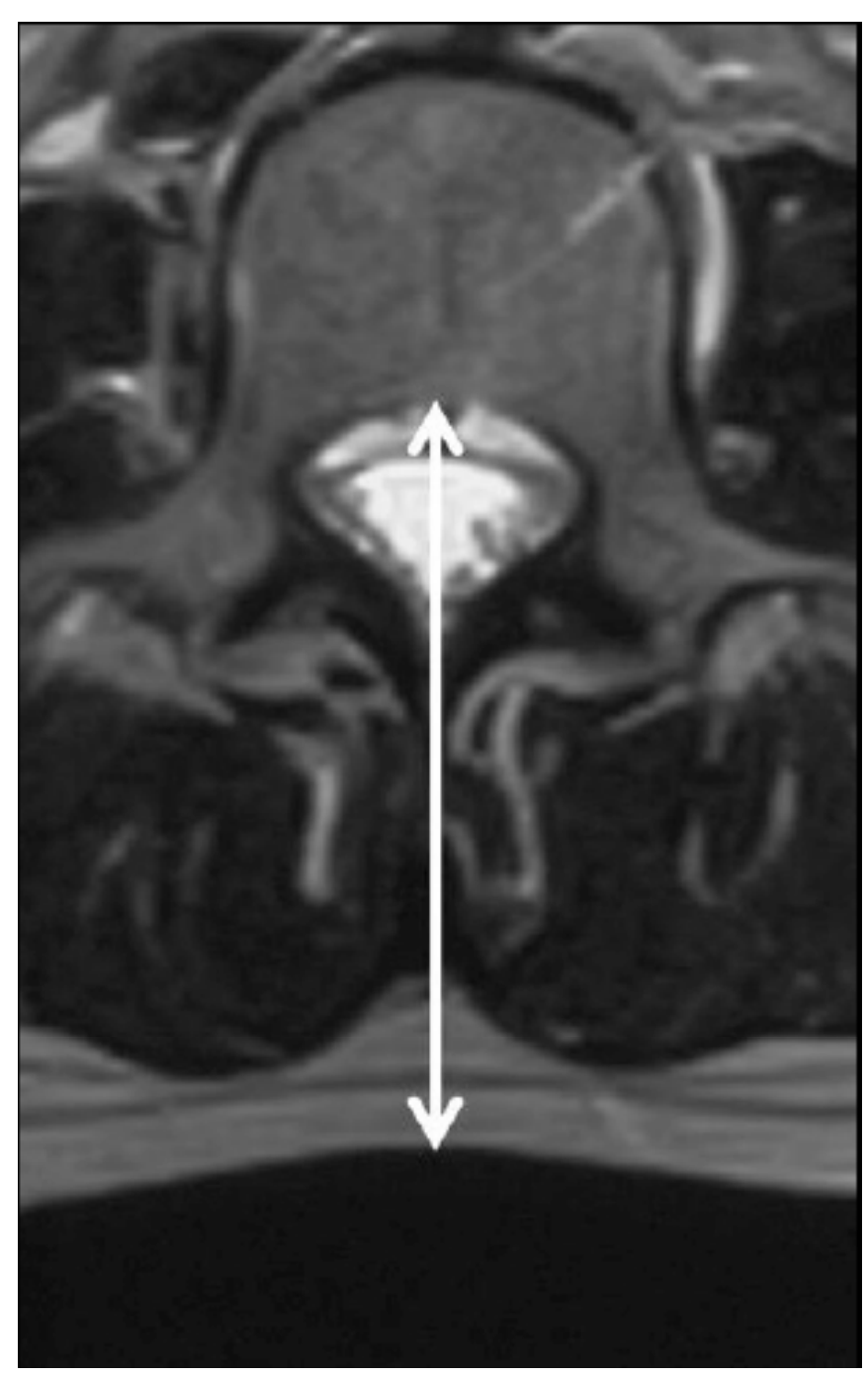

Fig. (1). Distance in a straight line between the skin surface and posterior margin of the vertebral body.

Table 1 shows the age and gender of patients in each group. As to the statistic investigation of 3 groups, KruskalWallis test was conducted first, and the results were assayed by Steel-Dwass method as a post-hoc test, handling $\mathrm{p}<0.05$ as a significant difference. Severely obese patients was significantly $(\mathrm{p}<0.01)$ younger than obese and non-obese patients. Regarding the number of male or female patients there was no significant difference among three groups.

Investigated items including operative time, volume of intraoperative bleeding, distance from skin surface to the posterior margin of the vertebral body, preoperative score based on the Japanese Orthopaedic Association (JOA) scoring system for lumbar spinal disorders (full mark; 29 points), JOA score approximately 2 years postoperatively, improvement rate of JOA score (Hirabayashi method), and intra- and postoperative complications were all compared between the three groups. Operative time was defined as the time from the start of operation to the end of suturing. Distance in a straight line between the skin surface and posterior margin of the vertebral body (Fig. 1) on computed tomography or magnetic resonance imaging were measured using the pointing device on the computer, with measurements performed twice to obtain the mean value. If multiple vertebral levels were operated on in surgery, the level providing the longest distance was chosen for measurement. 
Table 2. Clinical Results in Each Group

\begin{tabular}{|c|c|c|c|}
\hline & Preoperative JOA score (points) & Postoperative JOA score (points) & Improvement rate of JOA score (\%) \\
\hline \hline non-obese group & $13.4 \pm 5.2$ & $25.0 \pm 7.9$ & $74.5 \pm 23.7$ \\
\hline obese group & $12.9 \pm 5.7$ & $24.6 \pm 8.8$ & $72.8 \pm 28.9$ \\
\hline severely obese group & $11.3 \pm 6.1$ & $19.5 \pm 9.9$ & $46.3 \pm 25.4 *$ \\
\hline
\end{tabular}

$* p<0.01$.

\section{RESULTS}

Mean operative times were $163.6 \pm 46.7 \mathrm{~min}, 119.9 \pm 35.2$ $\min$ and $104.5 \pm 31.0 \mathrm{~min}$ for the severely obese, obese and non-obese groups, respectively. Operative time was significantly longer for the severely obese group than for the two other groups $(p<0.05)$. Mean volumes of intraoperative bleeding were $672.0 \pm 436.4 \mathrm{~mL}, 451.1 \pm 245.8 \mathrm{~mL}$ and 328.7 $\pm 221.2 \mathrm{~mL}$ for the severely obese, obese and non-obese groups, respectively, with a significantly larger volume in the severely obese group than in the other two groups $(p<0.05)$. While preoperative JOA score was slightly lower in the severely obese group than in the two other groups, improvement rate of JOA score 2 years after operation was significantly lower in the severely obese group than in the other groups $(p<0.01)$ (Table 2). Mean distances from skin surface to the posterior margin of the vertebral body were $10.1 \pm 2.4 \mathrm{~cm}, 7.5 \pm 2.4 \mathrm{~cm}$ and $6.8 \pm 2.3 \mathrm{~cm}$ for the severely obese, obese and non-obese groups, respectively, with a significantly longer distance apparent in the severely obese group than in the other two groups $(p<0.01)$.

Intra- and postoperative complications were observed in 6 of 12 severely obese patients $(50 \%)$, comprising incorrect insertion of the pedicle screw in 2 patients (Fig. 2), and injury of the dura mater, false recognition of vertebral level during surgery, fracture of the pedicle screw and transient motor paralysis in 1 patient each. Complications of deep infection $(n=1)$, and transient sensory paralysis $(n=1)$ were seen in 2 of the 38 obese patients $(5.3 \%)$. In the non-obese group, complications of injury of the dura mater $(n=1)$, transient motor paralysis $(\mathrm{n}=1)$ and fracture of the pedicle screw $(n=1)$ were observed in 3 of the 68 patients $(4.4 \%)$.
Complications occurred more frequently in the severely obese group than in the other groups.

\section{DISCUSSION}

In general, obese patients are known to be at high risk during systemic anesthesia $[9,10]$ and surgery and frequently develop perioperative complications $[11,12]$. In addition, patients with lumbar spinal disorders have been reported to frequently show extradural lipoma $[13,14]$ and readily develop deep vein thrombosis and pulmonary embolism [15].

Various studies have already assessed the influences of obesity on outcomes of lumbar surgery, with some reporting negative influences of obesity and others contradicting such findings. Andreshak et al. [16] noted little effect of obesity on the outcomes of lumbar surgery. Gepstein et al. [6] claimed that lumbar surgery was so effective even in obese patients that high BMI would not represent a contraindication for the surgery. Conversely, Patel et al. [17] reported that complications including infection, injury of the dura mater, deep vein thrombosis, pneumonia and position-related palsies occur significantly more often in obese patients after spinal surgery. LaCaille et al. [18] reported that worker's compensation costs for obese patients were approximately double those for non-obese patients due to the onset of complications and the apparently poor postoperative outcomes in obese patients. Furthermore, Garcia et al. [19] noted that obese patients with lumbar spine disorders did not lose weight even after spinal surgery, but instead had gained weight (mean, $2.5 \mathrm{~kg}$ ) by 3 years postoperatively, resulting in unimproved activities of daily living.

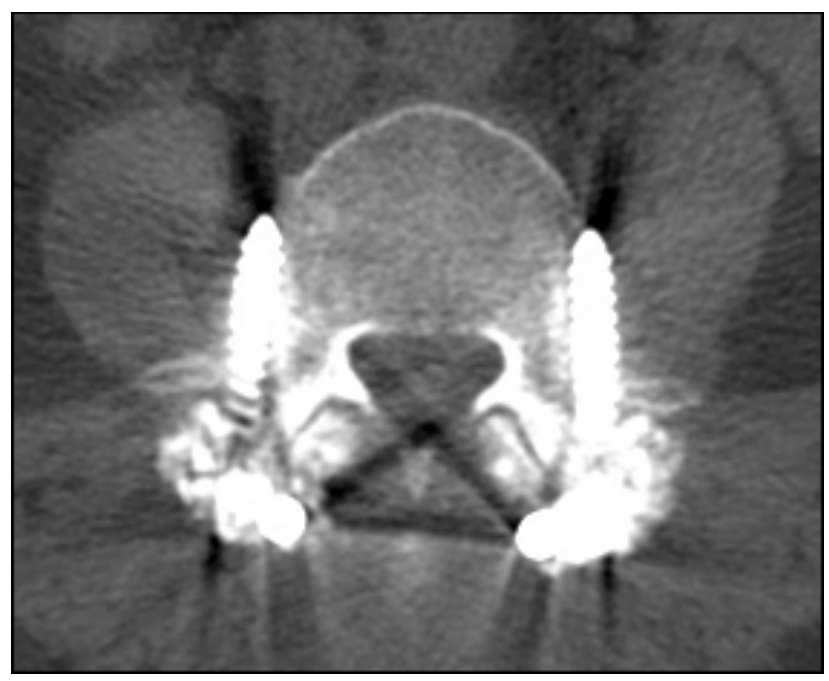

Fig. (2). A case (53 year-old female, severely obese group) with incorrect insertions of both pedicle screws in the L5 vertebra. 
The present study demonstrated that distance from the skin surface to the posterior margin of the vertebral body was longer in the severely obese group than in the obese and non-obese groups, and the operative field was thus prominently deep in severely obese patients. This deepness was considered to result in a poor operative field and reduced operability, leading to increased intraoperative complications such as incorrect screw insertion, injury of the dura mater, and false recognition of the vertebral level during surgery. Lumbar spinal surgery on severely obese patients may thus require ingenuity to achieve proper lighting of the operative field, possibly including the use of a microscope or endoscope [20], or insertion of the screw after opening the paraspinal muscles through the Wiltse paraspinal approach [21].

This research was conducted as a retrospective study. Since the number of cases was small and the follow-up period was short, we intend to increase the number of cases and conduct a prospective study in the future. The presence or absence of smoking and that of psychopsychiatric disposition were not investigated in this research. Therefore, further research including the investigation of factors to influence the operation results of lumbar spinal canal stenosis in the future is considered necessary.

\section{CONCLUSION}

Longer operative time, increased intraoperative bleeding, longer distance from the skin surface to the posterior margin of the vertebral body, poor postoperative outcomes and higher incidences of intra- and postoperative complications were observed with surgery for lumbar spinal canal stenosis in severely obese patients (BMI $\geq 35$ ), compared to patients with BMI $<35$. Severely obese patients and their family members should thus receive sufficient explanation of the risks associated with surgery when obtaining informed consent.

\section{REFERENCES}

[1] Jenkins LT, Jones AL, Harma JJ. Prognostic factors in lumbar spinal fusion. Contemp Orthop 1994; 29: 173-80.

[2] Thomas NW, Rea GL, Pikul BK, Mervis LJ, Irsik R, McGregor JM. Quantitative outcome and radiographic comparisons between laminectomy and laminotomy in the treatment of acquired lumbar stenosis. Neurosurgery 1997; 41: 567-74.
[3] Carragee E, Alamin T, Cheng I, Franklin T, Hurwitz E. Does minor trauma cause serious low back illness? Spine (Phila Pa 1976) 2006; 31: 2942-9.

[4] Weiner BK, Patel R, Noble P. Randomized trials and registries: a computer simulation to study the impact of surgeon/patient factors on outcomes. Spine J 2008; 8: 953-67.

[5] Haro H, Masekawa S, Kamada Y. Prospective analysis of clinical evaluation and self-assessment by patients after decompression surgery for degenerative lumbar canal stenosis. Spine J 2008; 8: $380-4$.

[6] Gepstein R, Shabat S, Arinzon ZH, Berner Y, Catz A, Folman Y. Does obesity affect the results of lumbar decompressive spinal surgery in the elderly? Clin Orthop Relat Res 2004; 426: 138-44.

[7] Pan WH, Yeh WT, Weng LC. Epidemiology of metabolic syndrome in Asia. Asia Pac J Clin Nutr 2008; 17 (Suppl 1): 37-42.

[8] Telfeian AE, Reiter GT, Durham SR, Marcotte P. Spine surgery in morbidly obese patients. J Neurosurg(Spine 1) 2002; 97: 20-4.

[9] Fujinaga A, Fukushima Y, Kojima A, et al. Anesthetic management of an extremely obese patient. J Anesth 2007; 21: 261-4.

[10] Gonzalez H, Minville V, Delanoue K, Mazerolles M, Concina D, Fourcade O. The importance of increased neck circumference to intubation difficulties in obese patients. Anesth Analg 2008; 106 : 1132-6.

[11] Bult MJ, van Dalen T, Muller AF. Surgical treatment of obesity. Eur J Endocrinol 2008; 158: 135-45.

[12] Lubbeke A, Moons KG, Garavaglia G, Hoffmeyer P. Outcomes of obese and nonobese patients undergoing revision total hip arthroplasty. Arthritis Rheum 2008; 59: 738-45.

[13] Ishikawa Y, Shimada Y, Miyakoshi N, et al. Decompression of idiopathic lumbar epidural lipomatosis: diagnostic magnetic resonance imaging evaluation and review of the literature. J Neurosurg Spine 2006; 4: 24-30.

[14] Min WK, Oh CW, Jeon IH, Kim SY, Park BC. Decompression of idiopathic symptomatic epidural lipomatosis of the lumbar spine. Joint Bone Spine 2007; 74: 488-90.

[15] DeMaria EJ, Carmody BJ. Perioperative management of special population: obesity. Surg Clin North Am 2005; 85: 1283-9.

[16] Andreshak TG, An HS, Hall J, Stein B. Lumbar spine surgery in the obese patient. J Spin Disord 1997; 10: 376-9.

[17] Patel N, Bagan B, Vadera S, et al. Obesity and spine surgery: relation to perioperative complications. J Neurosurg Spine 2007; 6: 291-7.

[18] LaCaille RA, DeBerard MS, LaCaille LJ, Masters KS, Colledge AL. Obesity and litigation predict workers' compensation costs associated with interbody cage lumbar fusion. Spine J 2007; 7: 26672.

[19] Garcia RM, Messerschmitt PJ, Furey CG, Bohlman HH, Cassinelli EH. Weight loss in overweight and obese patients following successful lumbar decompression. J Bone Joint Surg Am 2008; 90: 742-7.

[20] Cole JS 4th, Jackson TR. Minimally invasive lumbar discectomy in obese patients. Neurosurgery 2007; 61: 539-44.

[21] Wiltse LL, Spencer CW. New uses and refinements of the paraspinal approach to the lumbar spine. Spine 1988; 13: 696-706.

Received: August 10, 2009

Revised: November 10, 2009

Accepted: November 13, 2009

(C) Furukawa et al.; Licensee Bentham Open.

This is an open access article licensed under the terms of the Creative Commons Attribution Non-Commercial License (http: //creativecommons.org/licenses/by$\mathrm{nc} / 3.0 /$ ), which permits unrestricted, non-commercial use, distribution and reproduction in any medium, provided the work is properly cited. 